\title{
Identification of CD14 as a potential biomarker of hepatocellular carcinoma using iTRAQ quantitative proteomics
}

\author{
Jiao Guo ${ }^{1, *}$, Rui Jing ${ }^{1,2, *}$, Jian-Hong Zhong ${ }^{3, *}$, Xin Dong ${ }^{1,4}$, Yun-Xi Li ${ }^{5}$, Yin-Kun Liu ${ }^{6}$, \\ Tian-Ren Huang ${ }^{1}$ and Chun-Yan Zhang ${ }^{1}$ \\ ${ }^{1}$ Experimental Department, Affiliated Tumor Hospital of Guangxi Medical University, Nanning, Guangxi, PR China \\ ${ }^{2}$ Hematology Department, Affiliated Hospital of Binzhou Medical University, Yantai, Shandong, PR China \\ ${ }^{3}$ Hepatobiliary Surgery Department, Affiliated Tumor Hospital of Guangxi Medical University, Nanning, Guangxi, PR China \\ ${ }^{4}$ Oncology Department, Affiliated Hospital of Binzhou Medical University, Yantai, Shandong, PR China \\ ${ }^{5}$ Cancer Registry Department, People's Hospital of Fusui County, Fusui, Guangxi, PR China \\ ${ }^{6}$ Liver Cancer Institute, Zhongshan Hospital, Fudan University, Yangpu, Shanghai, PR China \\ *These authors have contributed equally to this work \\ Correspondence to: Chun-Yan Zhang, email: zcy_263@163.com \\ Tian-Ren Huang, email: huangtianrencn@163.com \\ Yin-Kun Liu, email: liu.yinkun@zs-hospital.sh.cn \\ Keywords: hepatocellular carcinoma (HCC), diagnosis, biomarker, iTRAQ, CD 14 \\ Received: March 26, $2017 \quad$ Accepted:May 14, $2017 \quad$ Published: June 28, 2017 \\ Copyright: Guo et al. This is an open-access article distributed under the terms of the Creative Commons Attribution License 3.0 \\ (CC BY 3.0), which permits unrestricted use, distribution, and reproduction in any medium, provided the original author and source \\ are credited.
}

\section{ABSTRACT}

Hepatocellular carcinoma (HCC) is one of the most common malignant tumors without effective diagnostic biomarkers. This study intended to dynamically analyze serum proteomics in different pathological stages of liver diseases, and discover potential diagnostic biomarkers for early HCC. Patients with hepatitis B virus (HBV) infection, liver cirrhosis (LC), or HCC together with healthy controls (HC) were enrolled. Proteins differentially expressed between groups were screened using isobaric tagging for relative and absolute quantitation (iTRAQ), and promising HCC biomarker candidates were subjected to bioinformatics analysis, including K-means clustering, gene ontology (GO) and string network analysis. Potential biomarkers were validated by Western blotting and enzyme-linked immunosorbent assay (ELISA), and their diagnostic performance was evaluated using receiver operating characteristic (ROC) curve analysis. Finally, 93 differentially expressed proteins were identified, of which 43 differed between HBV and HC, 70 between LC and HC, and 51 between HCC and HC. Expression levels of gelsolin (GELS) and sulfhydryl oxidase 1 (QSOX1) varied with disease state as follows: HC < HBV < LC < HCC. The reverse trend was observed with CD14. These ITRAQ results were confirmed by Western blotting and ELISA. Logistic regression and ROC curve analysis identified the optimal cut-off for alpha-fetoprotein (AFP), CD14 and AFP/CD14 was 191.4 $\mathrm{ng} / \mathrm{mL}$ (AUC $0.646,95 \%$ CI $0.467-0.825$, sensitivity $31.6 \%$, specificity $94.4 \%$ ), $3.16 \mathrm{ng} / \mathrm{mL}$ (AUC $0.760,95 \%$ CI $0.604-0.917$, sensitivity $94.7 \%$, specificity $50 \%$ ) and $0.197 \mathrm{ng} / \mathrm{mL}$ (AUC $0.889,95 \%$ CI $0.785-0.993$, sensitivity $84.2 \%$, specificity $83.3 \%$ ) respectively. In conclusion, Assaying CD14 levels may complement AFP measurement for early detection of HCC. 


\section{INTRODUCTION}

Hepatocellular carcinoma (HCC) is one of the most common malignant tumors, ranking sixth in morbidity and third in mortality worldwide $[1,2]$. The high frequency of early metastasis means that $\mathrm{HCC}$ is usually at an advanced stage when diagnosed, reducing the likelihood that the patient can benefit from curative surgical treatment. Therefore, early detection of HCC, such as through assay of serum biomarkers, is of tremendous importance.

Serum alpha-fetoprotein (AFP), although the most widely used biomarker for HCC diagnosis in the clinic, is less than satisfactory because of its low specificity and sensitivity [3]. Numerous other candidate HCC biomarkers have been proposed, including lens culinaris agglutinin reactive AFP (AFP-L3), des- $\gamma$-carboxy prothrombin (DCP), prothrombin produced by vitamin $\mathrm{K}$ absence or antagonism II (PIVKA II), Golgi protein-73 (GP73), glypican-3 (GPC3), $\gamma$-glutamyl transferase (GGT), $\alpha$-L-fucosidase (AFU), and alpha1-antitrypsin and apolipoprotein $\mathrm{J}$ (Apo-J) [4-8]. All have substantial shortcomings that severely limit their clinical usefulness. Studies are needed to identify novel HCC biomarkers with superior early diagnostic potential.

Isobaric tagging for relative and absolute quantitation (iTRAQ) has emerged as a powerful proteomic technology for sensitively and accurately searching for tumor biomarkers [9]. This technique relies on identifying proteins differentially expressed between, for example, a healthy and disease state, thereby allowing identification of disease markers. The traditional method of identifying differentially expressed proteins is twodimensional gel electrophoresis, but this is poorly suited for detecting proteins that have a high molecular weight, are highly acidic or basic, or reside in the cell membrane [10]. The iTRAQ technique does not have such limitations, and it offers high throughput: proteins from up to 8 samples can be analyzed and quantified simultaneously $[9,11]$. In addition to being simple and sensitive, the technique shows good repeatability, with a coefficient of variation between 0.04 and 0.14 [12]. When coupled with liquid chromatography-tandem mass spectrometry (LC-MS/MS), iTRAQ has proven successful at identifying disease-specific biomarkers and targets [13]. Here we used the iTRAQ technique coupled with LC-MS/MS to identify candidate serum biomarkers for early detection of HCC.

Guangxi is a high endemic area of HCC in China, and further we have established a high-risk population cohort comprised of more than 3,800 members with nested case-control study method since 2003. Serum samples from these individuals have been regularly collected since 2003, together with their medical status, including the results of early cancer screening and detection [14]. This specimen bank therefore provides the possibility of identifying serum biomarkers closely linked with $\mathrm{HCC}$, as well as assessing their potential involvement in $\mathrm{HCC}$ onset and progression, especially the transition from HBV infection to HCC. We therefore applied the iTRAQ technique coupled with LC-MS/ MS to identify candidate serum biomarkers for early detection of HCC based on the serum samples of highrisk population cohort.

\section{RESULTS}

\section{Study population}

A total of 100 participants were screened initially, and 23 participants were excluded because they had secondary liver cancer that had metastasized from other primary regions, or they had a history of other solid tumors. In the end, 77 participants were enrolled, of whom 40 participated in the discovery phase (10 each with HCC, LC, HBV, or HC). The remaining 37 participated in the validation phase: 19 with HCC and 18 with LC (Figure 1). The cause of LC patients was HBV infection and the cause of HCC patients was liver cirrhosis developed from HBV. The detailed demographic and clinical characteristics of participants were shown in Table 1 .

\section{Depletion of high-abundance serum proteins}

After MARS chromatography, pooled serum samples were separated into low- and high-abundance proteins. The following high-abundance proteins were largely eliminated: albumin, immunoglobulin G ( $\operatorname{IgG})$, antitrypsin, immunoglobulin A (IgA), transferrin, haptoglobin, fibrinogen, alpha2-macroglobulin, alpha1acid glycoprotein, transthyretin, complement 3 (C3), apolipoprotein A-I (apoA-I), apolipoprotein A-II (apoAII), and immunoglobulin M (IgM). Quantity One software analysis indicated that MARS removed $94 \%$ of highabundance proteins, which significantly enriched the samples for low-abundance proteins (Figure 2).

\section{iTRAQ-LC-MS/MS analysis of serum proteins}

Of the 280 proteins analyzed in the discovery phase, 93 were found to be differentially expressed between at least two of the four participant groups. Relative to the $\mathrm{HC}$ group, 43 proteins were differentially expressed in the HBV group, 70 in the LC group and 51 in the HCC group. (Tables 2-5) We also identified several proteins that were differentially expressed among more than two groups. We chose to focus on these as potential HCC biomarkers because of the possibility that their expression level correlates with pathological stage of liver disease. We found that GELS was persistently up-regulated in more advanced disease: $\mathrm{HBV} / \mathrm{HC}=$ $1.280(p=0.028), \mathrm{LC} / \mathrm{HBV}=1.489(p=0.001)$, and HCC / $\mathrm{LC}=1.150(p=0.019)$. We observed a similar result 
Table 1: Demographic and clinical characteristics of participants

\begin{tabular}{|c|c|c|c|c|c|}
\hline & & $\mathrm{HCC}$ & $\mathbf{L C}$ & HBV & $\mathrm{HC}$ \\
\hline \multirow[t]{4}{*}{ Screening stage } & Gender (Male : Female) & $8: 2$ & $7: 3$ & $6: 4$ & $7: 3$ \\
\hline & Age (years) & $50(35-61)$ & $45.5(31-63)$ & $41.1(36-47)$ & $50.1(37-60)$ \\
\hline & HBV DNA (IU/mL, log) & $4.27 \pm 1.01$ & $4.12 \pm 1.2$ & $3.4 \pm 0.93$ & $/ *$ \\
\hline & Treatment Status & $\mathrm{N}$ & $\mathrm{N}$ & $\mathrm{N}$ & l \\
\hline \multirow[t]{4}{*}{ Validation stage } & Gender (Male : Female) & $14: 5$ & $11: 7$ & / & / \\
\hline & Age (years) & $50.3(37-59)$ & $47.6(34-56)$ & l & l \\
\hline & HBV DNA & $4.3 \pm 1.04$ & $4.6 \pm 1.01$ & l & l \\
\hline & Treatment Status & $\mathrm{N}$ & $\mathrm{N}$ & / & / \\
\hline
\end{tabular}

HCC, hepatocellular carcinoma; LC, liver cirrhosis; HBV, hepatitis B virus infection; HC, healthy controls. N, receive no treatments; /, not applicable; *, HBV DNA levels of healthy controls were all lower than the minimum limit of detection.

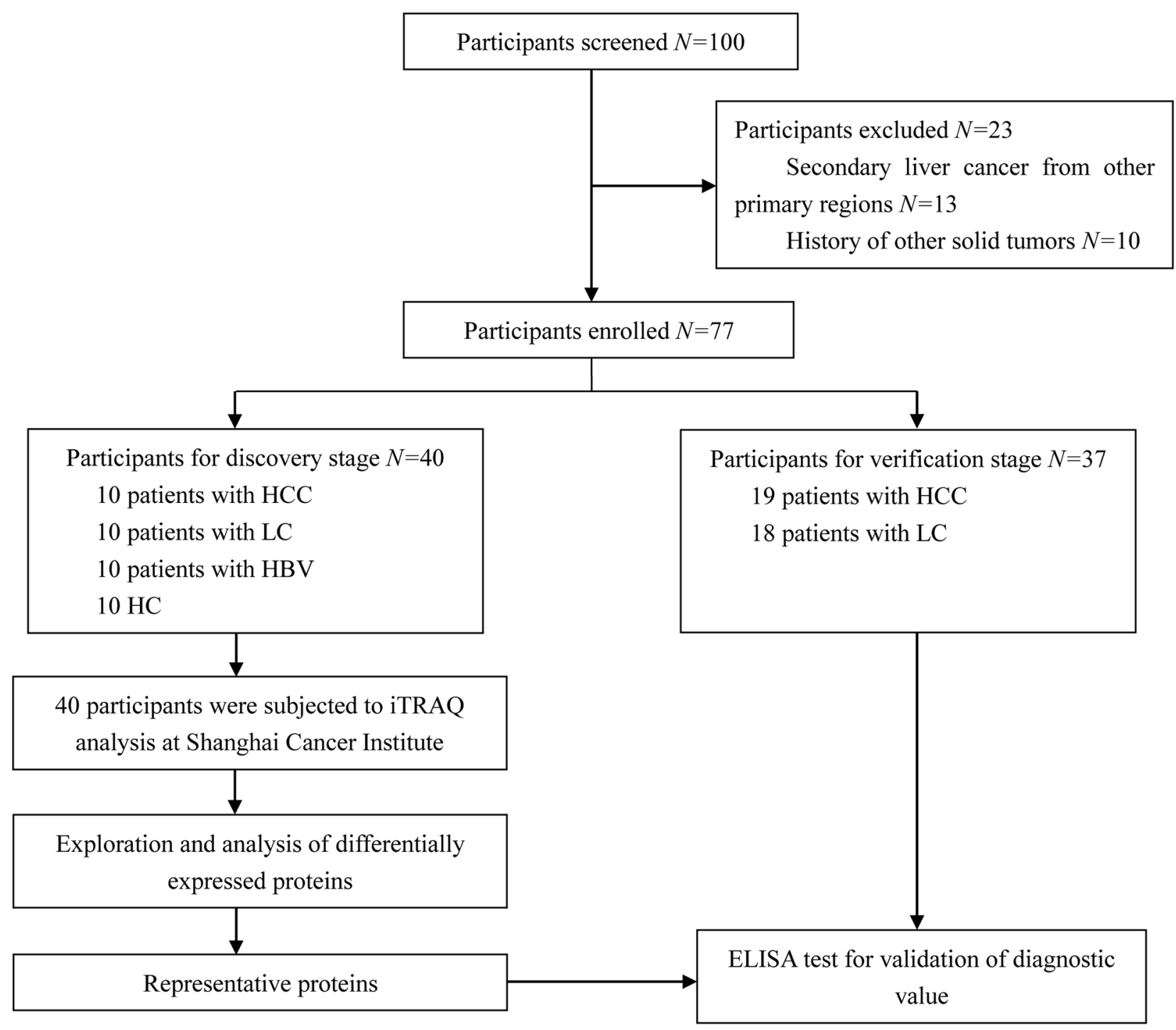

Figure 1: Flow diagram of participant screening and inclusion. HC: healthy controls; HBV: hepatitis B virus infection; LC: liver cirrhosis; HCC: hepatocellular carcinoma. 
with QSOX1: HBV / HC = $2.973(p=0.016), \mathrm{LC} / \mathrm{HBV}$ $=1.733(p=0.011)$, and HCC / LC $=1.350(p=0.004)$. Conversely, CD14 was persistently down-regulated in more advanced disease: LC / HBV $=0.433(p=0.035)$ and $\mathrm{HCC} / \mathrm{LC}=0.429(p=0.019)$ (Figure 3)

\section{Bioinformatic analysis}

Bioinformatics was used to classify proteins on the basis of change trends, biological process, molecular function and subcellular localization. Figure 4 summarizes the tendency patterns for differentially expressed proteins. A total of 36 types of K-means patterns were acquired: patterns 4 and 34 showed a trend of increasing protein expression under HCC conditions, while patterns 2, 9 and 19 showed a trend of increasing expression under HBV conditions, followed by a trend of decreasing expression under LC and HCC conditions. Further analysis showed that proteins in patterns 4 and 34 were involved mainly in metabolism, while proteins in patterns 2, 9 and 19 were mainly complementary proteins. GO analysis suggested that proteins were located mainly in the extracellular matrix (53\%) and they participated mainly in biological regulation (33\%), metabolism (25\%) and immune responses (14\%). Molecular functions were mainly protein binding
(37\%) and enzymatic activity (35\%) (Figure 5). String network analysis identified various possible interactions among the proteins, with several linked to more than 4 interactors (Figure 6).

\section{Validation of CD14, GELS and QSOX1 by Western blot}

CD14, GELS and QSOX1 were chosen for further validation. The main reason was that their expression difference was more obvious among different groups and the consistent up- or down-regulation observed may indicate a relatively stable and continuous function in disease progression. Consistent with the MS analysis, Western blotting showed progressive up-regulation of GELS and QSOX1 with more advanced liver disease, and progressive down-regulation of CD14 with more advanced disease (Figure 7).

\section{Quantification of CD14 by ELISA}

As a further validation of the biomarker screening, we used ELISA to measure CD14 levels in HCC and LC serum samples. Levels were compared using the approximate $t$ test because of the heterogeneity of sample variance. CD14 levels were significantly lower in the HCC

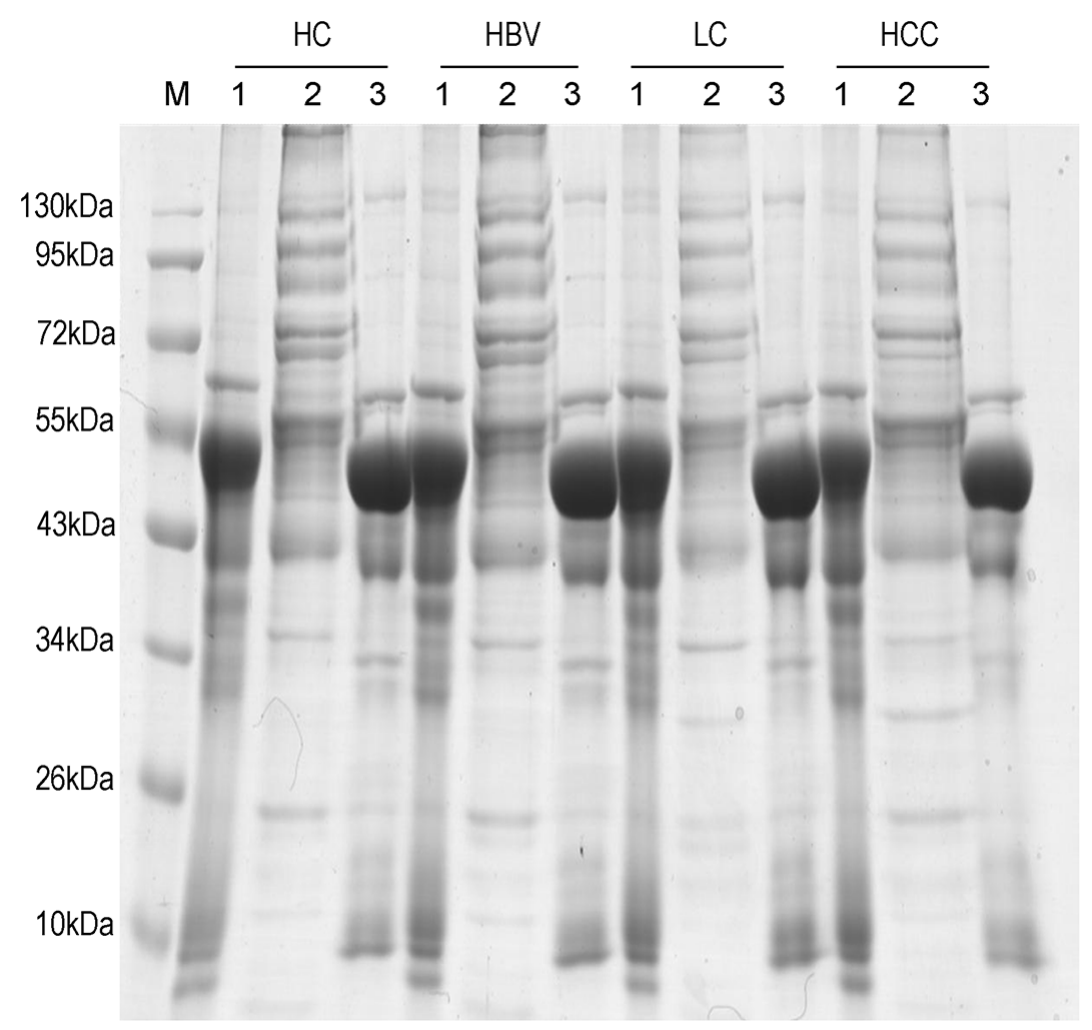

Figure 2: Sodium dodecyl sulfate polyacrylamide gel electrophoresis (SDS-PAGE) of serum after depletion of highabundance proteins. Lane M: molecular weight markers; lane 1: crude serum; lane 2: low-abundance proteins; lane 3: high-abundance proteins. HC: healthy controls; HBV: hepatitis B virus infection; LC: liver cirrhosis; HCC: hepatocellular carcinoma. 
Table 2: List of proteins differentially expressed between groups of hepatitis B virus infection and healthy controls

\begin{tabular}{|c|c|c|c|}
\hline Accession & Protein name & iTRAQ ratio (HBV/HC) & $\boldsymbol{P}$ \\
\hline A2AP & Alpha-2-antiplasmin & 0.603 & 0.011 \\
\hline A2MG & Alpha-2-macroglobulin & 6.982 & $<0.001$ \\
\hline AFAM & Afamin & 1.837 & 0.001 \\
\hline AMBP & Protein AMBP & 0.391 & 0.036 \\
\hline ANGT & Angiotensinogen & 0.387 & 0.027 \\
\hline ANT3 & Antithrombin-III & 0.545 & $<0.001$ \\
\hline APOA1 & Apolipoprotein A-I & 2.754 & $<0.001$ \\
\hline APOA2 & Apolipoprotein A-II & 3.499 & 0.019 \\
\hline APOA4 & Apolipoprotein A-IV & 1.459 & 0.013 \\
\hline APOC1 & Apolipoprotein C-I & 0.211 & 0.039 \\
\hline APOC2 & Apolipoprotein C-II & 2.109 & 0.010 \\
\hline APOE & Apolipoprotein E & 0.34 & 0.004 \\
\hline C1S & Complement $\mathrm{C} 1$ s subcomponent & 1.786 & 0.018 \\
\hline CERU & Ceruloplasmin & 0.581 & $<0.001$ \\
\hline CFAH & Complement factor $\mathrm{H}$ & 1.803 & 0.010 \\
\hline CFAI & Complement factor I & 1.472 & 0.018 \\
\hline $\mathrm{CO3}$ & Complement C3 & 0.565 & 0.025 \\
\hline $\mathrm{CO} 7$ & Complement component $\mathrm{C} 7$ & 1.706 & 0.025 \\
\hline FCN3 & Ficolin-3 & 2.128 & 0.027 \\
\hline FETUA & Alpha-2-HS-glycoprotein & 3.664 & 0.013 \\
\hline HBA & Hemoglobin subunit alpha & 0.331 & 0.006 \\
\hline HBB & Hemoglobin subunit beta & 0.337 & 0.016 \\
\hline HPT & Haptoglobin & 0.56 & $<0.001$ \\
\hline HRG & Histidine-rich glycoprotein & 0.356 & 0.020 \\
\hline IC1 & Plasma protease $\mathrm{C} 1$ inhibitor & 0.667 & 0.048 \\
\hline IGHA1 & Ig alpha- 1 chain $\mathrm{C}$ region & 5.105 & 0.044 \\
\hline IGHG3 & Ig gamma-3 chain $\mathrm{C}$ region & 4.966 & $<0.001$ \\
\hline IGHM & Ig mu chain $\mathrm{C}$ region & 7.656 & $<0.001$ \\
\hline IGKC & Ig kappa chain $\mathrm{C}$ region & 6.368 & 0.004 \\
\hline IGLL5 & Immunoglobulin lambda-like polypeptide 5 & 2.831 & 0.039 \\
\hline ITIH1 & Inter-alpha-trypsin inhibitor heavychain $\mathrm{H} 1$ & 0.603 & 0.008 \\
\hline ITIH2 & Inter-alpha-trypsin inhibitor heavychain $\mathrm{H} 2$ & 0.655 & 0.009 \\
\hline K1C9 & Keratin, type I cytoskeletal 9 & 4.207 & 0.003 \\
\hline K22E & Keratin, type II cytoskeletal 2 epidermal & 3.373 & 0.030 \\
\hline $\mathrm{K} 2 \mathrm{C} 1$ & Keratin, type II cytoskeletal 1 & 4.613 & 0.001 \\
\hline LUM & Lumican & 1.803 & 0.037 \\
\hline NRP1 & Neuropilin-1 & 2.535 & 0.003 \\
\hline
\end{tabular}




\begin{tabular}{llcc}
\hline Accession & Protein name & iTRAQ ratio (HBV/HC) & $\boldsymbol{P}$ \\
\hline PEDF & Pigment epithelium-derived factor & 1.57 & 0.020 \\
RET4 & Retinol-binding protein 4 & 0.506 & 0.020 \\
THRB & Prothrombin & 1.837 & 0.048 \\
TRFE & Serotransferrin & 1.923 & 0.002 \\
VTDB & Vitamin D-binding protein & 0.586 & 0.012 \\
ZA2G & Zinc-alpha-2-glycoprotein & 0.466 & 0.028 \\
\hline
\end{tabular}

$\mathrm{HBV}$, hepatitis B virus infection; HC, healthy controls.

samples $(\mathrm{F}=22.487, p=0.005$; Figure 8$)$, consistent with the MS analysis.

\section{Logistic regression and ROC curve analysis}

The logistic equation was as follows: $\ln [\mathrm{p} /(1-$ p) $]=-2.532-0.002 \times \mathrm{CD} 14-0.016 \times \mathrm{AFP}$, where $\mathrm{p}$ refers to the probability of HCC. Receiver operating characteristic (ROC) curves were generated to validate the diagnostic value of the model (Figure 9). The results indicated that the optimal diagnostic cut-off for AFP was $191.4 \mathrm{ng} / \mathrm{mL}$ [area under the curve (AUC) 0.646, $95 \%$ CI $0.467-0.825$, sensitivity $31.6 \%$, specificity $94.4 \%$ ), the optimal cut-off for CD14 was $3.16 \mathrm{ng} /$
$\mathrm{mL}$ (AUC 0.760, 95\%CI 0.604-0.917, sensitivity $94.7 \%$, specificity $50 \%$ ), and the optimal cut-off for the combination of AFP and CD14 was $0.197 \mathrm{ng} / \mathrm{mL}$ (AUC $0.889,95 \%$ CI $0.785-0.993$, sensitivity $84.2 \%$, specificity $83.3 \%$ ). Logistic regression suggested that for the combination of the two serum biomarkers, overall accuracy was $81.1 \%$; positive predictive value, $89.5 \%$; and negative predictive value, $72.2 \%$.

\section{DISCUSSION}

HCC, the most common histological type of liver neoplasms, is a highly lethal disease difficult to

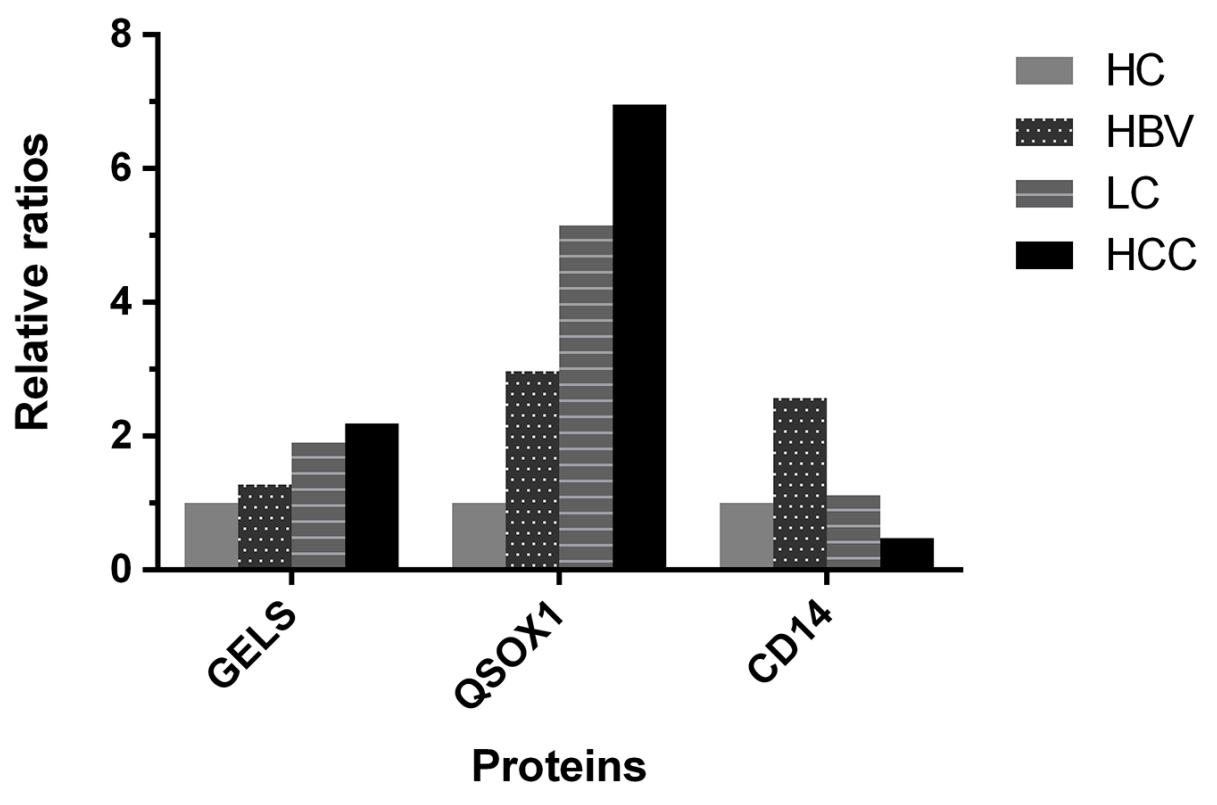

Figure 3: Relative ratios of three differentially expressed proteins (GELS, QSOX1 and CD14) compared with the HC group. The protein was up-regulated with the relative ratio $>1$ and down-regulated with the relative ratio $<1$. GELS: gelsolin; QSOX1: sulfhydryl oxidase 1; HC: healthy controls; HBV: hepatitis B virus infection; LC: liver cirrhosis; HCC: hepatocellular carcinoma. 
Table 3: List of proteins differentially expressed between groups of liver cirrhosis and healthy controls

\begin{tabular}{|c|c|c|c|}
\hline Accession & Protein name & iTRAQ ratio (LC/HC) & $\boldsymbol{P}$ \\
\hline A1AG2 & Alpha-1-acid glycoprotein 2 & 0.256 & 0.031 \\
\hline A1AT & Alpha-1-antitrypsin & 1.624 & 0.001 \\
\hline A1BG & Alpha-1B-glycoprotein & 2.128 & 0.001 \\
\hline A2AP & Alpha-2-antiplasmin & 0.296 & 0.005 \\
\hline A2GL & Leucine-rich alpha-2-glycoprotein & 1.514 & 0.036 \\
\hline A2MG & Alpha-2-macroglobulin & 5.2 & $<0.001$ \\
\hline $\mathbf{A A C T}$ & Alpha-1-antichymotrypsin & 0.433 & 0.025 \\
\hline AFAM & Afamin & 1.722 & 0.024 \\
\hline ALS & Insulin-like growth factor-binding protein complex acid labile subunit & 0.322 & $<0.001$ \\
\hline АМBP & Protein AMBP & 0.347 & 0.027 \\
\hline ANGT & Angiotensinogen & 0.38 & 0.015 \\
\hline ANT3 & Antithrombin-III & 0.377 & $<0.001$ \\
\hline APOA1 & Apolipoprotein A-I & 0.466 & 0.031 \\
\hline APOA2 & Apolipoprotein A-II & 0.203 & 0.045 \\
\hline APOA4 & Apolipoprotein A-IV & 2.831 & $<0.001$ \\
\hline APOM & Apolipoprotein M & 0.166 & 0.044 \\
\hline C1QA & Complement $\mathrm{C} 1 \mathrm{q}$ subcomponent subunit $\mathrm{A}$ & 1.977 & 0.010 \\
\hline C1QB & Complement $\mathrm{C}$ 1q subcomponent subunit $\mathrm{B}$ & 3.133 & 0.003 \\
\hline C1R & Complement $\mathrm{C} 1 \mathrm{r}$ subcomponent & 0.337 & 0.048 \\
\hline C4BPA & C4b-binding protein alpha chain & 0.27 & 0.026 \\
\hline CD5L & CD5 antigen-like & 3.342 & 0.012 \\
\hline CERU & Ceruloplasmin & 0.337 & $<0.001$ \\
\hline CFAB & Complement factor B & 0.322 & $<0.001$ \\
\hline CFAH & Complement factor $\mathrm{H}$ & 0.225 & $<0.001$ \\
\hline CFAI & Complement factor I & 0.296 & 0.001 \\
\hline CNDP1 & Beta-Ala-His dipeptidase & 0.225 & 0.032 \\
\hline $\mathrm{CO} 2$ & Complement $\mathrm{C} 2$ & 0.334 & 0.004 \\
\hline $\mathrm{CO3}$ & Complement C3 & 4.571 & 0.002 \\
\hline $\mathrm{CO5}$ & Complement C5 & 0.429 & $<0.001$ \\
\hline $\mathrm{CO6}$ & Complement component $\mathrm{C} 6$ & 0.429 & 0.039 \\
\hline $\mathrm{CO} 7$ & Complement component $\mathrm{C} 7$ & 6.73 & $<0.001$ \\
\hline CXCL7 & Platelet basic protein & 0.127 & 0.003 \\
\hline F13B & Coagulation factor XIII B chain & 0.592 & 0.028 \\
\hline FA5 & Coagulation factor $\mathrm{V}$ & 0.217 & 0.032 \\
\hline FETUA & Alpha-2-HS-glycoprotein & 3.467 & $<0.001$ \\
\hline FINC & Fibronectin & 0.592 & 0.001 \\
\hline GELS & Gelsolin & 1.355 & 0.029 \\
\hline
\end{tabular}

(Continued) 


\begin{tabular}{|c|c|c|c|}
\hline Accession & Protein name & iTRAQ ratio (LC/HC) & $\boldsymbol{P}$ \\
\hline HBA & Hemoglobin subunit alpha & 0.242 & 0.027 \\
\hline HEMO & Hemopexin & 0.278 & $<0.001$ \\
\hline HEP2 & Heparin cofactor 2 & 0.406 & 0.002 \\
\hline HPT & Haptoglobin & 0.251 & $<0.001$ \\
\hline IC1 & Plasma protease $\mathrm{C} 1$ inhibitor & 0.637 & $<0.001$ \\
\hline IGHG3 & Ig gamma-3 chain $\mathrm{C}$ region & 7.516 & $<0.001$ \\
\hline IGHM & Ig mu chain $\mathrm{C}$ region & 5.395 & 0.005 \\
\hline IGKC & Ig kappa chain $\mathrm{C}$ region & 10.375 & 0.001 \\
\hline IPSP & Plasma serine protease inhibitor & 2.704 & 0.035 \\
\hline ITIH1 & Inter-alpha-trypsin inhibitor heavy chain H1 & 0.278 & $<0.001$ \\
\hline ITIH2 & Inter-alpha-trypsin inhibitor heavy chain $\mathrm{H} 2$ & 0.344 & $<0.001$ \\
\hline ITIH4 & Inter-alpha-trypsin inhibitor heavy chain $\mathrm{H} 4$ & 0.525 & 0.022 \\
\hline K2C1 & Keratin, type II cytoskeletal 1 & 4.831 & 0.011 \\
\hline KAIN & Kallistatin & 0.429 & 0.038 \\
\hline KLKB1 & Plasma kallikrein & 0.273 & $<0.001$ \\
\hline KNG1 & Kininogen-1 & 0.319 & 0.002 \\
\hline KV313 & Ig kappa chain V-III region HIC & 3.048 & 0.025 \\
\hline LUM & Lumican & 2.655 & $<0.001$ \\
\hline PEDF & Pigment epithelium-derived factor & 1.905 & 0.024 \\
\hline PLMN & Plasminogen & 0.256 & $<0.001$ \\
\hline PRG4 & Proteoglycan 4 & 0.24 & 0.021 \\
\hline PROS & Vitamin K-dependent protein S & 0.244 & 0.035 \\
\hline QSOX1 & Sulfhydryl oxidase 1 & 7.447 & 0.020 \\
\hline RET4 & Retinol-binding protein 4 & 0.421 & 0.019 \\
\hline SAMP & Serum amyloid P-component & 0.143 & 0.003 \\
\hline SEPP1 & Selenoprotein P & 2.355 & 0.018 \\
\hline THRB & Prothrombin & 0.479 & 0.032 \\
\hline TRFE & Serotransferrin & 0.479 & $<0.001$ \\
\hline TSP1 & Thrombospondin-1 & 0.141 & $<0.001$ \\
\hline VTDB & Vitamin D-binding protein & 0.425 & $<0.001$ \\
\hline VTNC & Vitronectin & 0.283 & 0.002 \\
\hline VWF & von Willebrand factor & 6.31 & 0.001 \\
\hline ZPI & Protein Z-dependent protease inhibitor & 0.402 & 0.002 \\
\hline
\end{tabular}

LC, liver cirrhosis; HC, healthy controls. 
Table 4: List of proteins differentially expressed between groups of hepatocellular carcinoma and healthy controls

\begin{tabular}{|c|c|c|c|}
\hline Accession & Name & iTRAQ ratio (HCC/HC) & $\boldsymbol{P}$ \\
\hline A1AG2 & Alpha-1-acid glycoprotein 2 & 0.57 & 0.022 \\
\hline A1AT & Alpha-1-antitrypsin & 1.995 & 0.002 \\
\hline A1BG & Alpha-1B-glycoprotein & 0.667 & 0.032 \\
\hline A2AP & Alpha-2-antiplasmin & 0.752 & 0.037 \\
\hline A2MG & Alpha-2-macroglobulin & 2.032 & $<0.001$ \\
\hline AACT & Alpha-1-antichymotrypsin & 0.731 & 0.041 \\
\hline ACTG & Actin, cytoplasmic 2 & 2.148 & 0.001 \\
\hline AFAM & Afamin & 3.162 & $<0.001$ \\
\hline ALS & $\begin{array}{l}\text { Insulin-like growth factor-binding protein complex acid } \\
\text { labile subunit }\end{array}$ & 0.344 & 0.001 \\
\hline ANT3 & Antithrombin-III & 0.363 & $<0.001$ \\
\hline APOA2 & Apolipoprotein A-II & 14.723 & $<0.001$ \\
\hline APOA4 & Apolipoprotein A-IV & 0.347 & $<0.001$ \\
\hline C1S & Complement $\mathrm{C} 1 \mathrm{~s}$ subcomponent & 0.619 & 0.026 \\
\hline CBG & Corticosteroid-binding globulin & 0.492 & 0.021 \\
\hline CBPN & Carboxypeptidase $\mathrm{N}$ catalytic chain & 2.704 & 0.021 \\
\hline $\mathrm{CO} 2$ & Complement C2 & 2.831 & 0.031 \\
\hline $\mathrm{CO3}$ & Complement C3 & 9.727 & $<0.001$ \\
\hline CO5 & Complement C5 & 1.629 & 0.029 \\
\hline $\mathrm{CO} 7$ & Complement component $\mathrm{C} 7$ & 2.535 & 0.005 \\
\hline CO9 & Complement component C9 & 2.399 & 0.037 \\
\hline CPN2 & Carboxypeptidase $\mathrm{N}$ subunit 2 & 2.858 & 0.009 \\
\hline F13B & Coagulation factor XIII B chain & 0.353 & 0.008 \\
\hline FETA & Alpha-fetoprotein & 33.113 & 0.009 \\
\hline FETUA & Alpha-2-HS-glycoprotein & 0.291 & 0.026 \\
\hline FINC & Fibronectin & 0.238 & $<0.001$ \\
\hline GELS & Gelsolin & 2.938 & $<0.001$ \\
\hline HBA & Hemoglobin subunit alpha & 1.528 & 0.047 \\
\hline HBB & Hemoglobin subunit beta & 0.291 & 0.011 \\
\hline HEP2 & Heparin cofactor 2 & 0.555 & 0.010 \\
\hline HPT & Haptoglobin & 0.158 & $<0.001$ \\
\hline IC1 & Plasma protease $\mathrm{C} 1$ inhibitor & 0.219 & $<0.001$ \\
\hline IGHM & Ig mu chain $\mathrm{C}$ region & 2.109 & 0.002 \\
\hline IGKC & Ig kappa chain $\mathrm{C}$ region & 9.727 & 0.001 \\
\hline ITIH1 & Inter-alpha-trypsin inhibitor heavy chain H1 & 0.409 & 0.003 \\
\hline ITIH2 & Inter-alpha-trypsin inhibitor heavy chain $\mathrm{H} 2$ & 0.466 & $<0.001$ \\
\hline K1C10 & Keratin, type I cytoskeletal 10 & 11.272 & 0.035 \\
\hline
\end{tabular}

(Continued) 


\begin{tabular}{llcc}
\hline Accession & Name & iTRAQ ratio (HCC/HC) & $P$ \\
\hline K1C9 & Keratin, type I cytoskeletal 9 & 4.207 & 0.001 \\
K2C1 & Keratin, type II cytoskeletal 1 & 2.729 & 0.019 \\
K2C6C & Keratin, type II cytoskeletal 6C & 6.31 & $<0.001$ \\
KLKB1 & Plasma kallikrein & 0.57 & 0.010 \\
KNG1 & Kininogen-1 & 0.673 & 0.007 \\
KV313 & Ig kappa chain V-III region HIC & 3.532 & 0.016 \\
LBP & Lipopolysaccharide-binding protein & 5.058 & 0.001 \\
LUM & Lumican & 2.559 & 0.004 \\
PGRP2 & N-acetylmuramoyl-L-alanine amidase & 0.296 & 0.029 \\
RET4 & Retinol-binding protein 4 & 0.347 & 0.003 \\
TRFE & Serotransferrin & 0.174 & $<0.001$ \\
VTDB & Vitamin D-binding protein & 0.515 & 0.001 \\
VTNC & Vitronectin & 0.575 & 0.015 \\
VWF & von Willebrand factor & 4.446 & 0.008 \\
ZA2G & Zinc-alpha-2-glycoprotein & 0.625 & 0.012 \\
\hline
\end{tabular}

HCC, hepatocellular carcinoma; HC, healthy controls.

diagnose early and therefore treat aggressively. HCC carcinogenesis is known to be a multistage process often involving HBV infection and liver cirrhosis. Therefore we screened individuals at different stages of liver disease in order to capture dynamic changes in the serum proteome that might lead to the identification of novel serum biomarkers for detecting early HCC. Using high-throughput iTRAQ quantitative proteomics and a large-cohort serum bank, we identified 93 proteins differentially expressed between healthy controls and individuals with different stages of liver disease. And further we selected CD14, QSOX1 and GELS that were differentially expressed among the four groups for validation by Western blot or ELISA.

Functions are unknown for most of the differentially expressed proteins identified in our study. GO analysis suggests that most of these proteins are secreted and are involved in biological processes. K-means analysis identified 36 patterns, and string network analysis indicated various interactions among the proteins. Several of them, including AFP, apoA-I, apolipoprotein E (apoE), GELS, CD14, C3 and interalpha inhibitor H4 (ITIH4), mapped over four proteins in the network diagrams, and thus may play crucial roles in HCC detection. The reliability of our results is reflected in the fact that several proteins identified in our study as significantly up- or down-regulated in liver disease were reported to show a similar relationship in previous studies using a different methodology. In particular, AFP, C3, apoA-III, apoE, alpha-1-antitrypsin (A1AT),
ACTG (actin, cytoplasmic 2), ceruloplasmin (CERU) and serum paraoxonase/arylesterase 1 (PON1) were previously reported to be up-regulated as in our study, while apoA-I, serum amyloid P-component (SAMP), plasma serine protease inhibitor (IPSP) were reported to be down-regulated [15-23].

The difficulty of early diagnosing $\mathrm{HCC}$ is mainly attributed to the current serum biomarkers could not effectively distinguish HCC from LC. Thus in the validation phase of our study, we only recruited HCC and LC patients. The result indicated that AFP was unable to distinguish HCC from LC. Approximately one third of HCC patients do not express AFP, while it is expressed in just $20-60 \%$ of HBV and LC patients, [24] making it a less reliable HCC biomarker. In our study, CD14 was able to distinguish HCC from LC (p $<0.05$ ), so it may be a complementary biomarker for AFP in HCC diagnosis. Indeed, combining AFP and CD14 improved the diagnosis rate of HCC, increasing sensitivity to $84.2 \%$ and specificity to $83.3 \%$. CD14 is a glycoprotein comprising a membrane-bound part (mCD14) and a soluble part (sCD14). The mCD14 is mainly distributed on the surface of mononuclear cells, macrophages and dendritic cells, while sCD14 is secreted by mononuclear cells and exists in the serum of human and animals. Our Western and ELISA assays specifically recognized sCD14. This molecule appears to bind the bacterial endotoxin lipopolysaccharide (LPS) and help trigger host immune responses against the bacterial invader [25]. 
Table 5: List of proteins identified as differentially expressed both in the present study and in previous work

\begin{tabular}{llcc}
\hline Accession & Protein name & Expression trend & Reference \\
\hline AFP & Alpha-fetoprotein & $\uparrow$ & Li 2009 [18] \\
CERU & Ceruloplasmin & $\uparrow$ & Feng 2005 [16] \\
A1AT & Alpha-1-antitrypsin & $\uparrow$ & Feng 2005 [16] \\
& & $\uparrow 13[20]$ & Blanc 2005 [15] \\
APOE & Apolipoprotein E & Zhong 2012 [23] \\
APOA2 & & $\uparrow$ & Zhong 2012 [23] \\
PON1 & Apolipoprotein A-II & $\uparrow$ & Huang 2013 [17] \\
ACTG & Serum paraoxonase/arylesterase 1 & $\uparrow$ & Xu 2013 [22] \\
C3 & Actin, cytoplasmic 2 & $\uparrow$ & Steel 2003 [21] \\
APOA1 & Complement C3 & $\downarrow$ & Qin 2013 [20] \\
& Apolipoprotein A-I & & Zhong 2012 [23] \\
& & & Steel 2003 [21]
\end{tabular}

$\uparrow$ Up-regulated; $\downarrow$ Down-regulated.

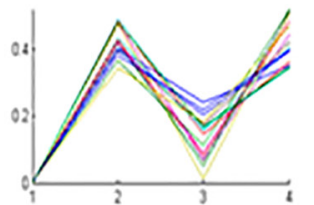

1

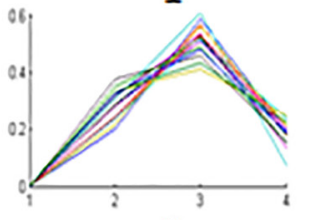

5
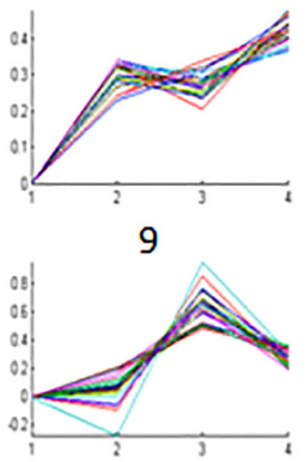

13

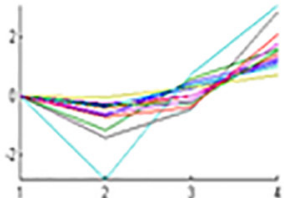

2

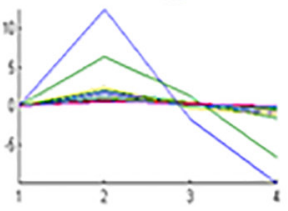

6

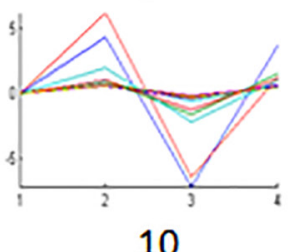

10

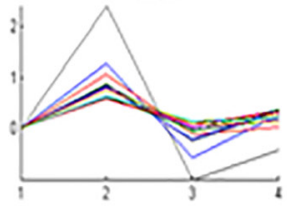

14

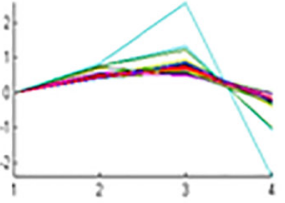

3
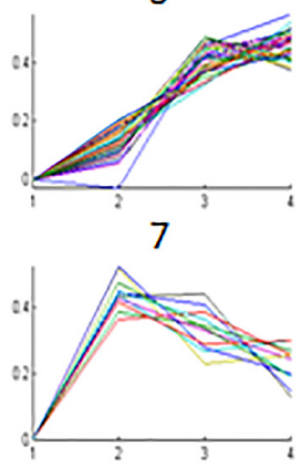

11

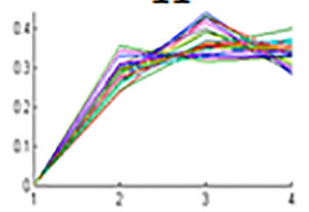

15

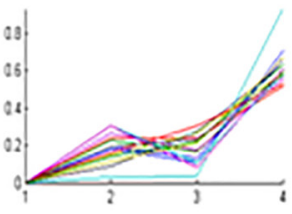

4
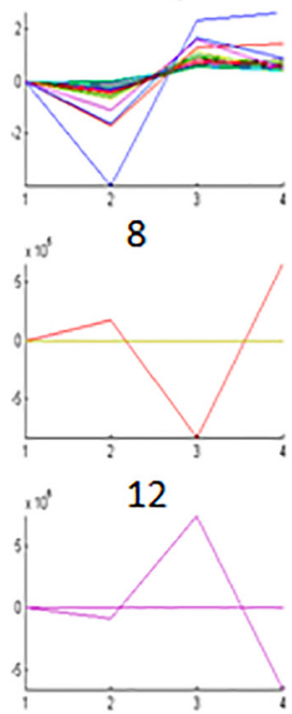

16

Figure 4: K-means cluster analysis of differentially expressed proteins. The abscissa represents the four groups: 1 (HC), 2 (HBV), 3 (LC) and 4 (HCC). The ordinate represents the expression patterns of the differentially expressed proteins. HC: healthy controls; HBV: hepatitis B virus infection; LC: liver cirrhosis; HCC: hepatocellular carcinoma. 


\section{A Cellular Component}

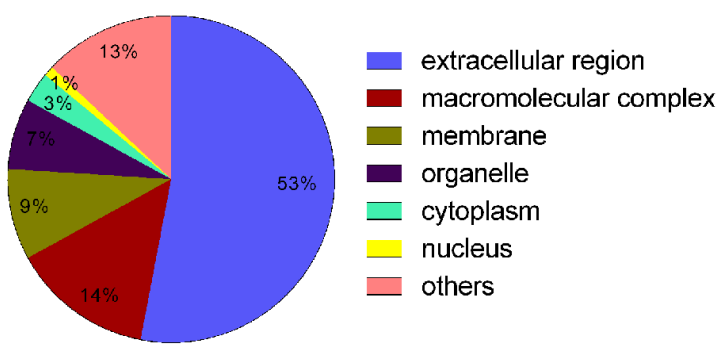

B Biological Process

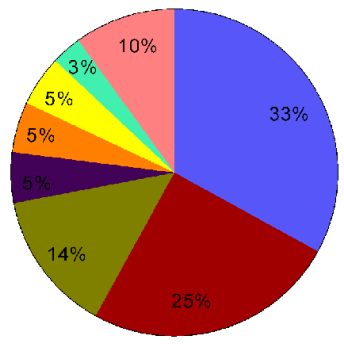

biological regulation

- metabolic process

$\square$ immune response

- cellular homeostasis

$\square$ cell adhesion

$\square$ signal transduction

$\square$ cell differentiation

$\square$ others
C Molecullar Function

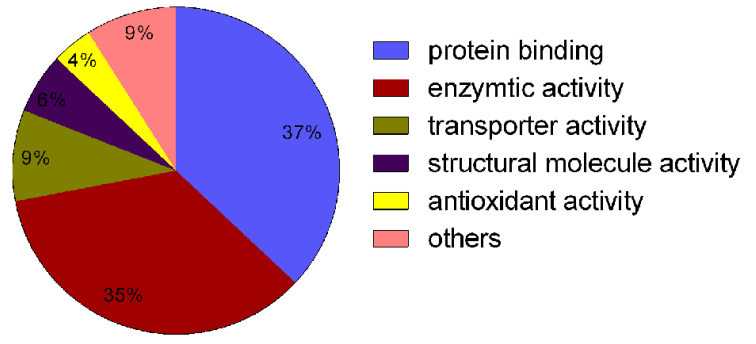

Figure 5: Gene ontology classification of differentially expressed proteins based on their cellular localization, biological process and molecular function. (A) Distribution of proteins based on their cellular localization. (B) Distribution of proteins based on their biological process. (C) Distribution of proteins based on their molecular function.

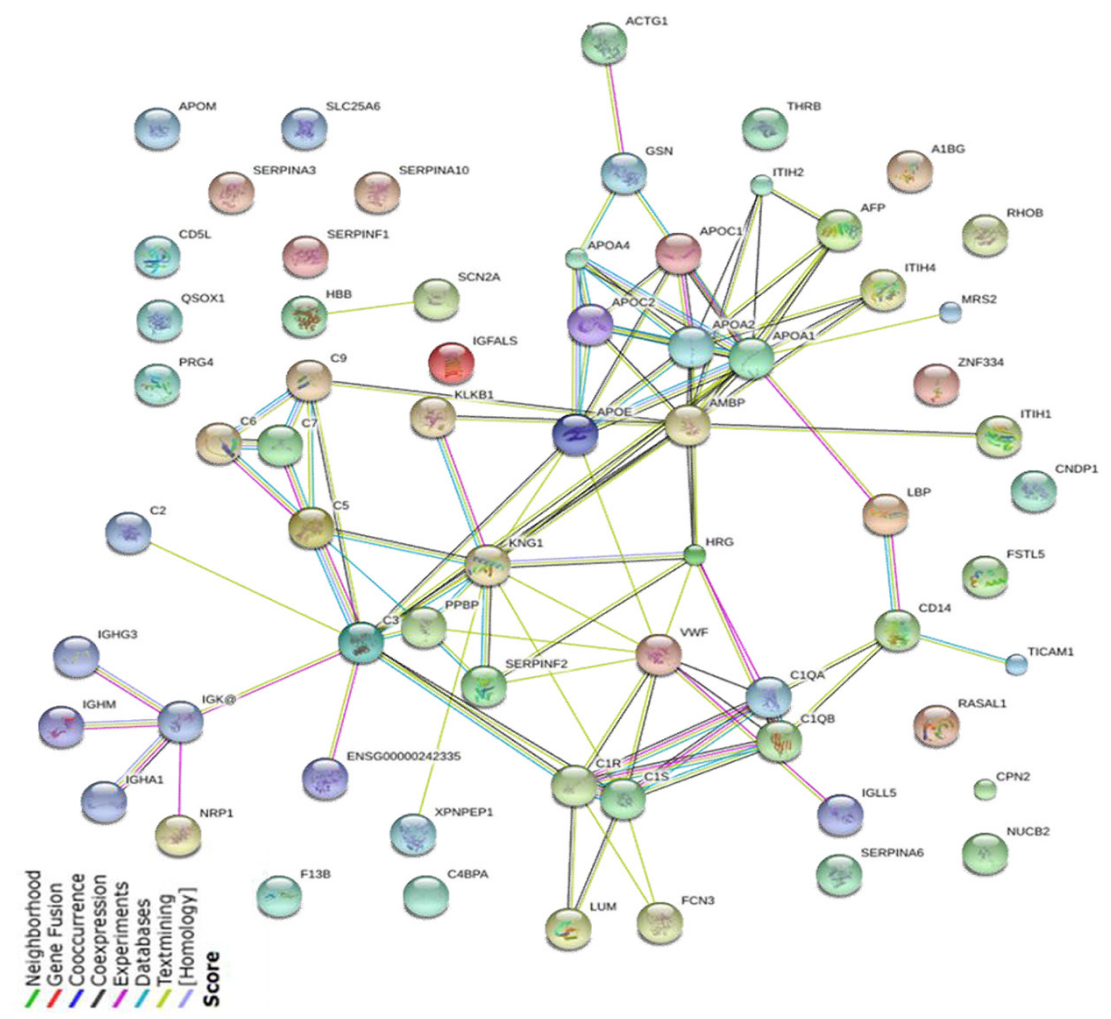

Figure 6: String network analysis of differentially expressed proteins identified by iTRAQ-LC-MS/MS. Lines with different colors represent the existence of different types of evidence applied to predict associations between proteins. 
The quantitative iTRAQ method has been used to investigate candidate biomarkers for a number of tumors, including oral cancer, [26] renal cell carcinoma, [27] breast cancer, [28] lung cancer, [29] ovarian cancer [30] as well as nasopharyngeal carcinoma [31]. While it has also been applied to the study of HCC,
[17, 32-35] we are aware of only one study focusing on HCC diagnosis, and the authors employed mainly cell lines [32]. The present study relied on serum samples from patients specifically recruited because their liver disease was prior to HCC or in early stages of HCC. Samples came from a large cohort of HBsAg-positive

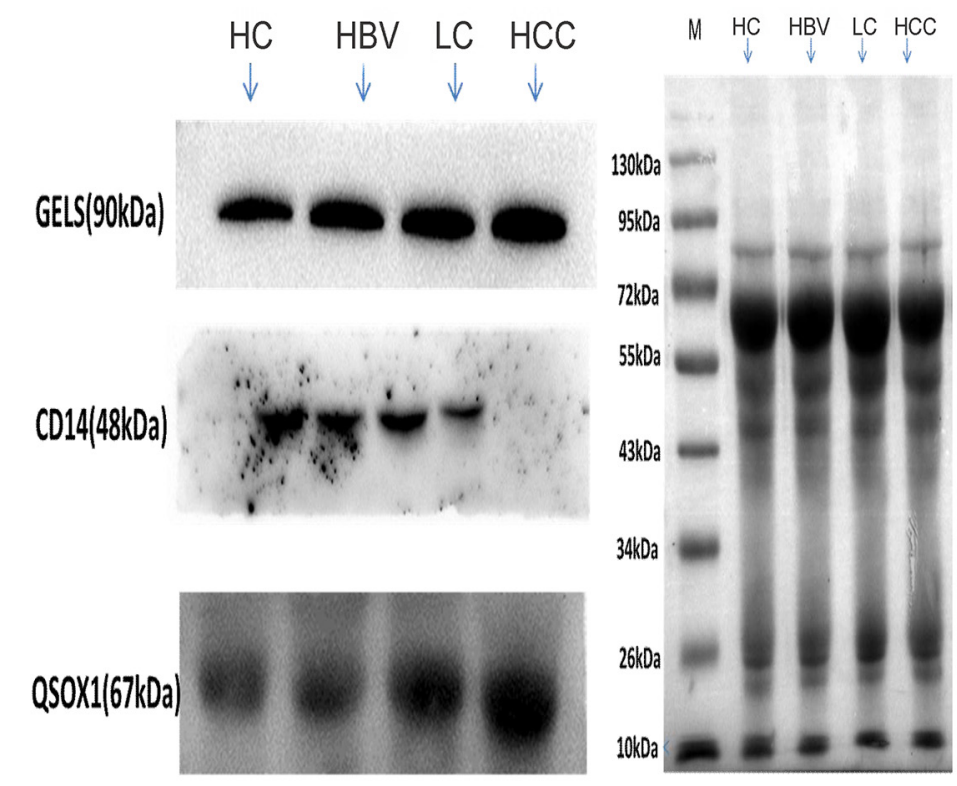

Figure 7: Validation of three differentially expressed proteins (GELS, QSOX1 and CD14) by Western blot analysis. The grey value of the serum protein stripe, which was measured after staining the PVDF membrane with MemCode, was used as an internal control. GELS: gelsolin; QSOX1: sulfhydryl oxidase 1; HC: healthy controls; HBV: hepatitis B virus infection; LC: liver cirrhosis; HCC: hepatocellular carcinoma.

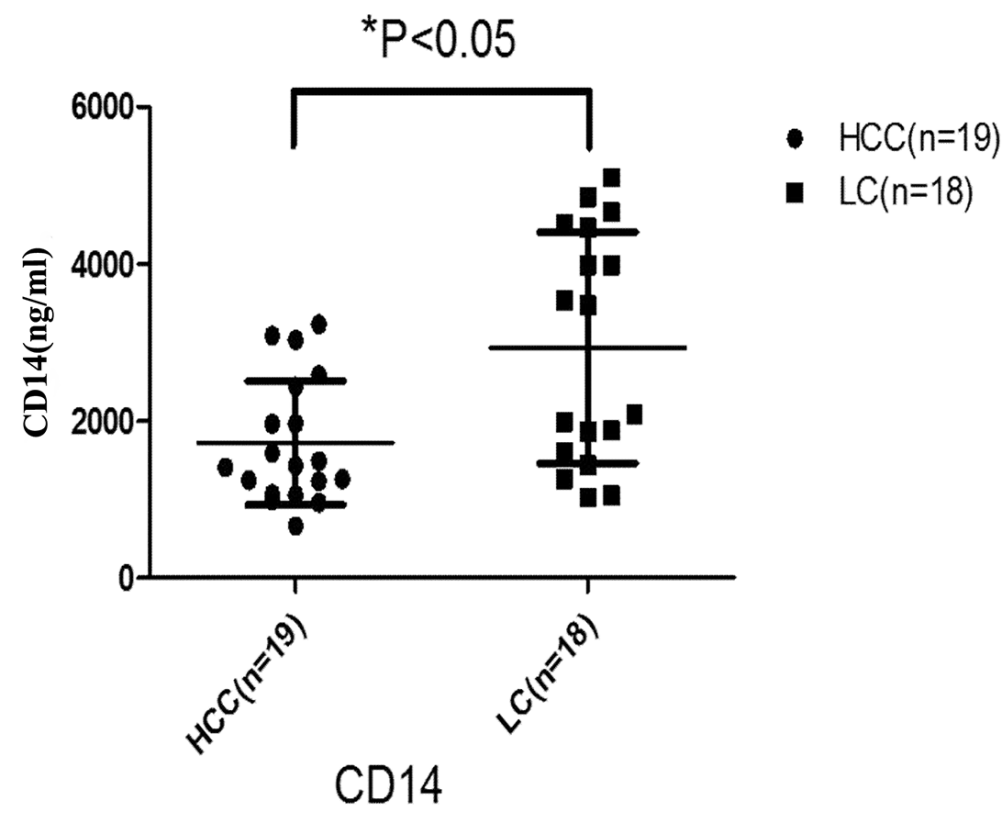

Figure 8: Serum concentration of CD14 in HCC and LC groups. The LC group showed a significantly higher level ( $\mathrm{p}=0.003)$. Black horizontal lines are means, and error bars are SEs. LC: liver cirrhosis; HCC: hepatocellular carcinoma. 


\section{ROC Curve}

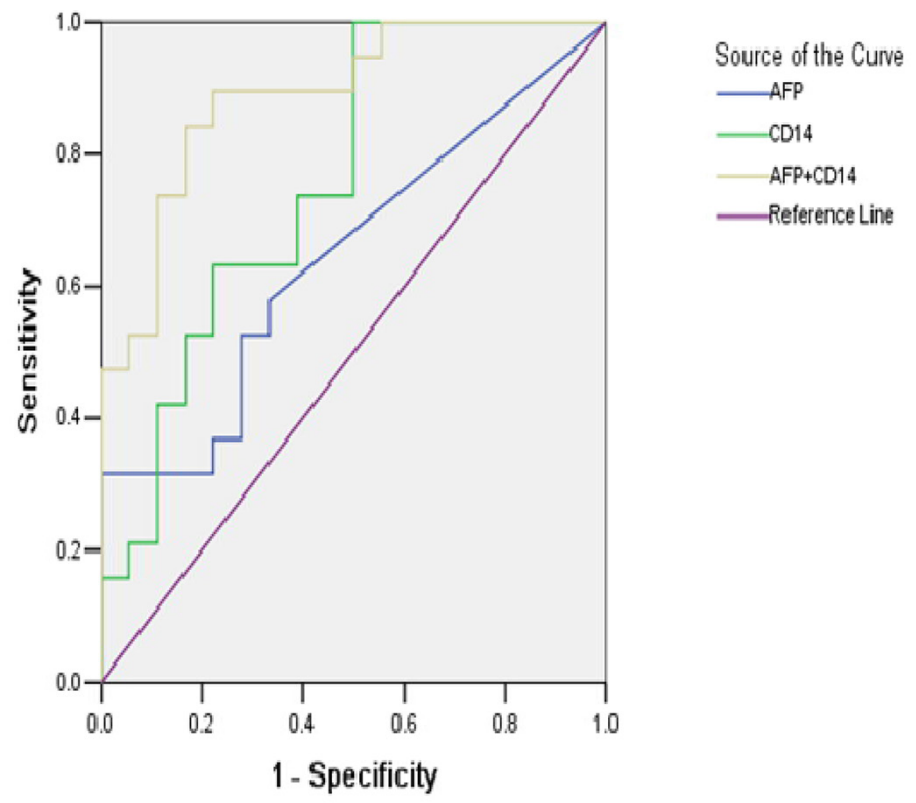

Figure 9: Receiver operating characteristic (ROC) curves for AFP alone, CD14 alone and their combination in the diagnosis of HCC. AUC: area under ROC curve; AFP: alpha-fetoprotein; HCC: hepatocellular carcinoma.

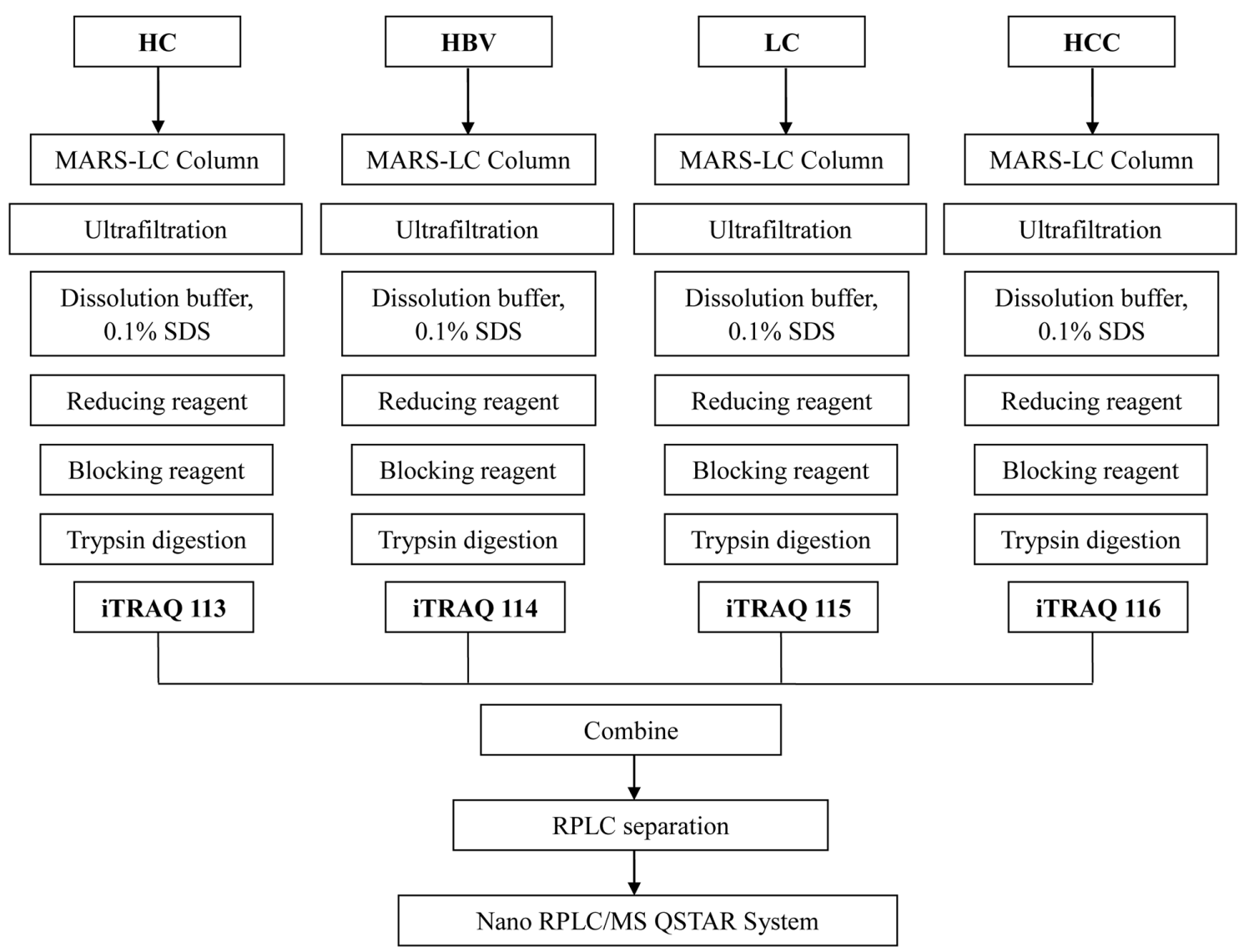

Figure 10: Flow diagram describing the process of iTRAQ-LC-MS/MS. HC: healthy controls; HBV: hepatitis B virus infection; LC: liver cirrhosis; HCC: hepatocellular carcinoma. 
individuals at high risk of liver cancer who were living in an area of China with endemic liver cancer. These individuals have been followed up and their serum sampled regularly since 2003. This specimen bank and database is uniquely suited to allowing analysis of serum proteins that may correlate with HCC onset and progression. The present work represents a substantial first step in this direction.

Furthermore, all the patients with $\mathrm{HCC}$ in our study recruited from this specimen bank had cirrhosis and all HBV patients received no treatments. Thus, we can rule out the impact of these factors. However, the relatively small sample size enrolled in the verification phase may reduce the reliability of the conclusion. Therefore, further studies of large cohorts of patients are needed to investigate the functions of the differentially expressed proteins we identified and further validate the diagnostic value of CD14 alone or in combination with other biomarkers such as AFP. The discovery approach here, and the serum specimen bank on which it is based, may be useful for detecting HCC early enough to allow aggressive, curative surgery to become an option for more patients.

\section{MATERIALS AND METHODS}

\section{Ethics statement}

This work was approved by the Research Ethics Committee of the Affiliated Tumor Hospital of Guangxi Medical University. Patient health, safety and privacy were protected throughout the study; serum and data collection were maintained anonymous. Written informed consent of all participants was obtained before the study began.

\section{Patients and serum samples}

The study involved consecutive series of patients with HCC (HCC group), liver cirrhosis (LC group), or chronic hepatitis $\mathrm{B}$ virus (HBV) infection recruited from the specimen bank which was established based on the serum samples of high incidence area of HCC in Fusui, Guangxi, China, between October 2010 and May 2012. In parallel, completely healthy controls (population-based HC group) from blood donor were also recruited. During the discovery phase using iTRAQ, 40 participants were analyzed, 10 from each group. During the validation phase, 19 HCC patients and 18 LC patients were enrolled. Serum samples were collected from the specimen bank between October 2010 and May 2012 and stored at $-80{ }^{\circ} \mathrm{C}$ until further analysis.

Primary HCC was diagnosed on the basis of ultrasound characteristics, serum level of alpha-fetoprotein (AFP), and histopathology results provided by the Affiliated Tumor Hospital of Guangxi Medical University in Guangxi, China. Diagnosis was carried out according to the guidelines of the American Association for the Study of Liver Diseases [36]. HBV infection was diagnosed based on the presence of HBsAg for 6 months prior to serum sampling, in accord with guidelines for preventing and treating chronic HBV infection [37]. Liver cirrhosis was diagnosed on the basis of histopathology of liver biopsy samples.

\section{Enrichment of low-abundance proteins}

Serum biomarkers of disease are expected to be lowabundance proteins, which means they can be masked by high-abundance proteins that account for approximately $90 \%$ of all serum proteins. In order to enrich for lowabundance proteins, [38] high-abundance proteins were depleted using the Agilent multiple affinity removal LC column-Human $14($ MARS, $4.6 \times 50 \mathrm{~mm}$, Agilent Technologies, Santa Clara, CA, USA) according to the manufacturer's instructions. In brief, serum samples were fractionated on MARS, and fractions were analyzed by SDS-PAGE and Coomassie blue staining to confirm the efficient removal of high-abundance proteins. Then relative band intensities were compared between different disease or control groups using Quantity One software (Bio-rad, USA).

\section{iTRAQ labeling}

Serum samples were mixed and dialyzed against dissolution buffer using spin concentrators with a 5-kDa molecular weight cut-off (Millipore Technologies, USA), then concentrated to approximately $50 \mathrm{ml}$. Proteins were deoxidized using tris (2-carboxyethyl) phosphine (TCEP), blocked using S-methyl methanethiosulfonate (MMTS), digested with trypsin, and finally labeled with 8-plex iTRAQ reagents. The $\mathrm{HC}$ sample was labeled with reagent 113; HBV sample, reagent 114; LC sample, reagent 115; and $\mathrm{HCC}$ sample, reagent 116. In a second run, these samples were labeled with, respectively, reagents 117,118 , 119 , and 121.

\section{LC-MS/MS analysis}

The iTRAQ-labeled serum samples were pooled and desalted on a C18 column (Sep-Pak vac, $1 \mathrm{cc}, 50$ mg, Waters, Germany). The desalted mixtures were diluted in buffer A (5\% acetonitrile, $94.5 \%$ water, $0.1 \%$ trifluoroacetic acid) and fractionated on a ZORBAX 300SB-C18 Column $(5 \mu \mathrm{m}, 300 \mathrm{~A}, 0.5 \times 23 \mathrm{~mm}$, Waters, Germany). connected to a 20AD HPLC system (Shimadzu, Kyoto, Japan). After chromatographic separation for $70 \mathrm{~min}$, the sample was eluted by applying a linear gradient of buffer B (95\% acetonitrile, 4.99\% water, $0.1 \%$ trifluoroacetic acid) from $5 \%$ to $35 \%$ over 53 min. Fractions were collected every $2 \mathrm{~min}$, giving a total of 35 fractions. 
Fractions were dried in a rotary vacuum concentrator and dissolved in buffer C (5\% acetonitrile, $0.1 \%$ trifluoroacetic acid). Peptides were separated on a ZORBAX 300SB-C18 Column (0.1 $315 \mathrm{~mm}, 5 \mathrm{~mm}$, $300 \AA$ A; Microm, Auburn, CA) by applying a linear gradient of buffer D (95\% acetonitrile, $4.99 \%$ water, $0.1 \%$ trifluoroacetic) from $5 \%$ to $35 \%$ over $70 \mathrm{~min}$. Eluted peptides were analyzed using a QSTAR XL system (Applied Biosystems Inc., USA) connected to a 20AD HPLC system (Shimadzu, Kyoto, Japan). Eluted peptides were scanned over the range of $400-1,800 \mathrm{~m} / \mathrm{z}$, and then over the range of $100-2,000 \mathrm{~m} / \mathrm{z}$. The pathway of iTRAQLC-MS/MS analysis is shown in Figure 10.

\section{Data analysis}

MS data were collected and identified using Analyst QS 1.1 software and ProteinPilot 3.0 software (Paragon Algorithm, Applied Biosystems Inc., USA). Raw data were analyzed using Applied Biosystems ProteinPilot software 4.5 (revision 1656). To qualify as differentially expressed proteins, they had to satisfy the following criteria: (1) proteins were present in the Swissprot database (SP HUMAN.fas) with a reported confidence interval $>95 \%$ (ProtScore $>1.3$ ); (2) proteins could be quantitated based on peak areas at $m / z 113,114,115,116,117,118,119$ and 121 ; (3) sampling error could be normalized using the bias correction function of the ProteinPilot software (Applied Biosystems Inc., USA); (4) Prot-Score (unused) $>1.3$, confidence interval $>95 \%$, EF $<2, \mathrm{P}<0.05$, together with the neighboring time points protein value $>1.2$ or $<0.8$.

Binary logistic regression was used to assess the diagnostic value of CD14 alone and together with AFP for detecting HCC. CD14 and AFP levels were treated as independent variables. The value of the dependent variable was set to 0 for HCC or 1 for LC. The ENTER method was applied to screen variables, and the threshold for statistical significance was defined as $\mathrm{p}<0.05$.

\section{Bioinformatic analysis}

All differentially expressed proteins identified in the discovery phase were analyzed using K-means clustering to characterize change trends; gene ontology $(\mathrm{GO})$ classification to identify potentially disease-related biological processes, molecular functions and subcellular localization; and string network analysis (http://string-db.org) to analyze the interaction between identified proteins. These analyses were supplemented using data from the Human Protein Reference Database (HPRD; www.hprd.org).

\section{Western blot analysis}

To validate a subset of differentially expressed proteins identified in iTRAQ-LC-MS/MS analysis as potential biomarkers for early HCC detection, the levels of these proteins in serum samples from different disease and control groups were analyzed by Western blotting. Protein samples $(20 \mu \mathrm{g})$ were separated by $10 \%$ SDSPAGE, and transferred to a PVDF membrane $(0.45$ $\mathrm{mm}$ thick). Membranes were stained with MemCode ${ }^{\mathrm{TM}}$ Reversible Protein Stain Kit (Pierce, USA) to check for consistent protein loading and transfer. Membranes were then blocked with Tris-buffered saline containing Tween-20 (TBST, $\mathrm{pH}$ 8.0) at room temperature for $1 \mathrm{~h}$, and incubated at $4{ }^{\circ} \mathrm{C}$ overnight with primary antibodies against candidate biomarkers CD14, gelsolin (GELS) and sulfhydryl oxidase 1 (QSOX1). Then membranes were incubated with horseradish peroxidaseconjugated secondary antibodies at room temperature for $1 \mathrm{~h}$. Membranes were washed three times in TBST, incubated for $5 \mathrm{~min}$ with ECL plus chemiluminescent immunoblotting detection system (GE Healthcare) and then exposed to X-ray film. The intensity of each band was normalized to total band intensity for the given sample.

\section{Quantification of CD14 by ELISA}

Levels of human CD14 in serum samples from 19 HCC patients and $18 \mathrm{LC}$ patients were assayed using a commercial ELISA kit (Human sCD14 Quantikine ELISA, R\&D, USA) according to the manufacturer's instructions. Experiments were performed in duplicate.

\section{Abbreviations}

$\mathrm{HCC}=$ hepatocellular carcinoma, $\mathrm{HC}=$ healthy controls, $\mathrm{HBV}=$ hepatitis $\mathrm{B}$ virus, $\mathrm{LC}=$ liver cirrhosis, $\mathrm{AFP}=$ alpha-fetoprotein, GELS = gelsolin, QSOX1 = sulfhydryl oxidase $1, \mathrm{GO}=$ gene ontology, iTRAQ = isobaric tagging for relative and absolute quantitation, ELISA = enzyme-linked immunosorbent assay, ROC = receiver operating characteristic, $\mathrm{AUC}=$ area under the curve, LC-MS/MS = liquid chromatography-tandem mass spectrometry.

\section{Author contributions}

JG, RJ, TRH, YKL and CYZ had full access to all data in the study and take responsibility for their integrity and the accuracy of the data analysis. TRH, CYZ and YKL conceived and designed the study. JG, RJ, JHZ and XD performed experiments. JG, RJ, JHZ and XD acquired data. JG, TRH, YKL and CYZ analyzed and interpreted data. JHZ, TRH, YXL and CYZ provided administrative, technical, or material support. JG, RJ, JHZ and XD wrote the article. TRH, YXL, CYZ and YKL critically reviewed the article for important intellectual content.

\section{CONFLICTS OF INTEREST}

The authors report no conflicts of interest in this work. 


\section{FINANCIAL SUPPORT}

This work was supported by the National Natural Science Foundation of China (81060173), Guangxi Natural Science Foundation (2010GXNSFA013242), the Medical and Health Care Appropriate Technology Research and Development Projects of Guangxi Province (S201417 and S201417-01), and the Innovation Project of Guangxi Graduate Education (YCSZ2015113). The funders had no role in study design, data collection and analysis, decision to publish, or preparation of the manuscript.

\section{REFERENCES}

1. Forner A, Llovet JM, Bruix J. Hepatocellular carcinoma. Lancet. 2012; 379:1245-1255.

2. Torre LA, Bray F, Siegel RL, Ferlay J, Lortet-Tieulent J, Jemal A. Global cancer statistics, 2012. CA Cancer J Clin. 2015; 65:87-108.

3. Forner A, Bruix J. Biomarkers for early diagnosis of hepatocellular carcinoma. Lancet Oncol. 2012; 13:750-751.

4. Waidely E, Al-Yuobi AO, Bashammakh AS, El-Shahawi MS, Leblanc RM. Serum protein biomarkers relevant to hepatocellular carcinoma and their detection. Analyst. 2016; 141:36-44.

5. Masuzaki R, Karp SJ, Omata M. New serum markers of hepatocellular carcinoma. Semin Oncol. 2012; 39:434-439.

6. Inagaki Y, Tang W, Makuuchi M, Hasegawa K, Sugawara Y, Kokudo N. Clinical and molecular insights into the hepatocellular carcinoma tumour marker des-gammacarboxyprothrombin. Liver Int. 2011; 31:22-35.

7. Comunale MA, Wang M, Rodemich-Betesh L, Hafner J, Lamontagne A, Klein A, Marrero J, Di Bisceglie AM, Gish R, Block T, Mehta A. Novel changes in glycosylation of serum Apo-J in patients with hepatocellular carcinoma. Cancer Epidemiol Biomarkers Prev. 2011; 20:1222-1229.

8. Comunale MA, Rodemich-Betesh L, Hafner J, Wang M, Norton P, Di Bisceglie AM, Block T, Mehta A. Linkage specific fucosylation of alpha-1-antitrypsin in liver cirrhosis and cancer patients: implications for a biomarker of hepatocellular carcinoma. PLoS One. 2010; 5:e12419.

9. Karp NA, Huber W, Sadowski PG, Charles PD, Hester SV, Lilley KS. Addressing accuracy and precision issues in iTRAQ quantitation. Mol Cell Proteomics. 2010; 9:1885-1897.

10. Van den Bergh G, Arckens L. Fluorescent two-dimensional difference gel electrophoresis unveils the potential of gelbased proteomics. Curr Opin Biotechnol. 2004; 15:38-43.

11. Prudova A, auf dem Keller U, Butler GS, Overall CM. Multiplex N-terminome analysis of MMP-2 and MMP-9 substrate degradomes by iTRAQ-TAILS quantitative proteomics. Mol Cell Proteomics. 2010; 9:894-911.
12. Wu WW, Wang G, Baek SJ, Shen RF. Comparative study of three proteomic quantitative methods, DIGE, cICAT, and iTRAQ, using 2D gel- or LC-MALDI TOF/TOF. J Proteome Res. 2006; 5:651-658.

13. Ruppen I, Grau L, Orenes-Pinero E, Ashman K, Gil M, Algaba F, Bellmunt J, Sanchez-Carbayo M. Differential protein expression profiling by iTRAQ-two-dimensional LC-MS/MS of human bladder cancer EJ138 cells transfected with the metastasis suppressor KiSS-1 gene. Mol Cell Proteomics. 2010; 9:2276-2291.

14. Zhang CY, Huang TR, Yu JH, Zhang ZQ, Li JL, Deng W, Ye SY, Zhou DN, He ZF. Epidemiological analysis of primary liver cancer in the early 21 st century in Guangxi province of China. Chin J Cancer. 2010; 29:545-550.

15. Blanc JF, Lalanne C, Plomion C, Schmitter JM, Bathany $\mathrm{K}$, Gion JM, Bioulac-Sage P, Balabaud C, Bonneu M, Rosenbaum J. Proteomic analysis of differentially expressed proteins in hepatocellular carcinoma developed in patients with chronic viral hepatitis C. Proteomics. 2005; 5:3778-3789.

16. Feng JT, Liu YK, Song HY, Dai Z, Qin LX, Almofti MR, Fang CY, Lu HJ, Yang PY, Tang ZY. Heat-shock protein 27: a potential biomarker for hepatocellular carcinoma identified by serum proteome analysis. Proteomics. 2005; 5:4581-4588.

17. Huang C, Wang Y, Liu S, Ding G, Liu W, Zhou J, Kuang M, Ji Y, Kondo T, Fan J. Quantitative proteomic analysis identified paraoxonase 1 as a novel serum biomarker for microvascular invasion in hepatocellular carcinoma. J Proteome Res. 2013; 12:1838-1846.

18. Li N, Long Y, Fan X, Liu H, Li C, Chen L, Wang Z. Proteomic analysis of differentially expressed proteins in hepatitis B virus-related hepatocellular carcinoma tissues. J Exp Clin Cancer Res. 2009; 28:122.

19. Marshall A, Lukk M, Kutter C, Davies S, Alexander G, Odom DT. Global gene expression profiling reveals SPINK1 as a potential hepatocellular carcinoma marker. PLoS One. 2013; 8:e59459.

20. Qin X, Chen Q, Sun C, Wang C, Peng Q, Xie L, Liu Y, Li $\mathrm{S}$. High-throughput screening of tumor metastatic-related differential glycoprotein in hepatocellular carcinoma by iTRAQ combines lectin-related techniques. Med Oncol. 2013; 30:420.

21. Steel LF, Shumpert D, Trotter M, Seeholzer SH, Evans AA, London WT, Dwek R, Block TM. A strategy for the comparative analysis of serum proteomes for the discovery of biomarkers for hepatocellular carcinoma. Proteomics. 2003; 3:601-609.

22. Xu K, Gao J, Yang X, Yao Y, Liu Q. Cytohesin-2 as a novel prognostic marker for hepatocellular carcinoma. Oncol Rep. 2013; 29:2211-2218.

23. Zhong DN, Ning QY, Wu JZ, Zang N, Wu JL, Hu DF, Luo SY, Huang AC, Li LL, Li GJ. Comparative proteomic profiles indicating genetic factors may involve in 
hepatocellular carcinoma familial aggregation. Cancer Sci. 2012; 103:1833-1838.

24. Shan SG, Gao YT, Xu YJ, Huang Y, Zhang Q, Zhai DK, Li JB, Wang FM, Jing X, Du Z, Wang YJ. Gradually increased Golgi protein 73 expression in the progression of benign liver diseases to precancerous lesions and hepatocellular carcinoma correlates with prognosis of patients. Hepatol Res. 2013; 43:1199-1210.

25. Nakamura S, Muro H, Suzuki S, Sakaguchi T, Konno H, Baba S, Syed AS. Immunohistochemical studies on endothelial cell phenotype in hepatocellular carcinoma. Hepatology. 1997; 26:407-415.

26. Lo WY, Wang HJ, Chiu CW, Chen SF. miR-27b-regulated TCTP as a novel plasma biomarker for oral cancer: from quantitative proteomics to post-transcriptional study. J Proteomics. 2012; 77:154-166.

27. Masui O, White NM, DeSouza LV, Krakovska O, Matta A, Metias S, Khalil B, Romaschin AD, Honey RJ, Stewart R, Pace K, Bjarnason GA, Siu KW, et al. Quantitative proteomic analysis in metastatic renal cell carcinoma reveals a unique set of proteins with potential prognostic significance. Mol Cell Proteomics. 2013; 12:132-144.

28. Shaheed SU, Rustogi N, Scally A, Wilson J, Thygesen H, Loizidou MA, Hadjisavvas A, Hanby A, Speirs V, Loadman P, Linforth R, Kyriacou K, Sutton CW. Identification of stage-specific breast markers using quantitative proteomics. J Proteome Res. 2013; 12:5696-5708.

29. Zeng GQ, Zhang PF, Deng X, Yu FL, Li C, Xu Y, Yi H, Li MY, Hu R, Zuo JH, Li XH, Wan XX, Qu JQ, et al. Identification of candidate biomarkers for early detection of human lung squamous cell cancer by quantitative proteomics. Mol Cell Proteomics. 2012; 11:M111.013946.

30. Karabudak AA, Hafner J, Shetty V, Chen S, Secord AA, Morse MA, Philip R. Autoantibody biomarkers identified by proteomics methods distinguish ovarian cancer from non-ovarian cancer with various CA-125 levels. J Cancer Res Clin Oncol. 2013; 139:1757-1770.

31. Feng $\mathrm{X}$, Zhang J, Chen WN, Ching CB. Proteome profiling of Epstein-Barr virus infected nasopharyngeal carcinoma cell line: identification of potential biomarkers by comparative iTRAQ-coupled 2D LC/MS-MS analysis. J Proteomics. 2011; 74:567-576.

32. Chaerkady R, Harsha HC, Nalli A, Gucek M, Vivekanandan P, Akhtar J, Cole RN, Simmers J, Schulick RD, Singh S, Torbenson M, Pandey A, Thuluvath PJ. A quantitative proteomic approach for identification of potential biomarkers in hepatocellular carcinoma. J Proteome Res. 2008; 7:4289-4298.

33. Yu Y, Pan X, Ding Y, Liu X, Tang H, Shen C, Shen H, Yang P. An iTRAQ based quantitative proteomic strategy to explore novel secreted proteins in metastatic hepatocellular carcinoma cell lines. Analyst. 2013; 138:4505-4511.

34. Liu Y, Wang X, Li S, Hu H, Zhang D, Hu P, Yang Y, Ren $\mathrm{H}$. The role of von Willebrand factor as a biomarker of tumor development in hepatitis B virus-associated human hepatocellular carcinoma: a quantitative proteomic based study. J Proteomics. 2014; 106:99-112.

35. Xing X, Huang Y, Wang S, Chi M, Zeng Y, Chen L, Li L, Zeng J, Lin M, Han X, Liu J, Liu X. Dataset for the quantitative proteomics analysis of the primary hepatocellular carcinoma with single and multiple lesions. Data Brief. 2015; 5:226-240.

36. Bruix J, Sherman M. Management of hepatocellular carcinoma: an update. Hepatology. 2011; 53:1020-1022.

37. Lok AS, McMahon BJ. Chronic hepatitis B: update 2009. Hepatology. 2009; 50:661-662.

38. Boylan KL, Andersen JD, Anderson LB, Higgins L, Skubitz AP. Quantitative proteomic analysis by iTRAQ(R) for the identification of candidate biomarkers in ovarian cancer serum. Proteome Sci. 2010; 8:31. 